\title{
The prevalence and clinical features of restless legs syndrome: A door to door population study in Orhangazi, Bursa in Turkey
}

\author{
Sevda Erer, Necdet Karli, Mehmet Zarifoglu, Alis Ozcakir ${ }^{1}$, Demet Yildiz ${ }^{1}$ \\ Departments of Neurology, ${ }^{1}$ Family Medicine, Uludag University School of Medicine, 16059 Bursa, Turkey
}

\section{Address for correspondence: Dr. Sevda Erer, \\ Department of Neurology, \\ Uludag University, School of \\ Medicine, Bursa-160 59, Turkey. \\ E-mail: sevdaerer@uludag.edu.tr, \\ sevdaerer@gmail.com}

\begin{abstract}
Background: Restless leg syndrome (RLS) has negative effects on the Quality of life of the patients. Epidemiological studies on RLS are limited. Aim: To determine the prevalence of RLS among people aged 40 years and above in Orhangazi district of Bursa, Turkey. Materials and Methods: The study was carried out between 2004 and 2005. This population-based study was conducted in two phases. In the phase I, residents conducted door-to-door interviews using a short Questionnaire to determine the possible cases of RLS. In the phase 2, physicians ascertained the suspected cases of RLS. Diagnosis of RLS was made using the criteria proposed by the International Restless Legs Syndrome Study Group (IRLSSG) and also the rating scale for RLS. Results: Out of I, 256 subjects screened in phase I, I, 124 (89.6\%) were included in the study. Also, 16I cases with suspected symptoms of RLS were detected in phase 1, 49 of the suspected cases could not be evaluated in phase 2. A diagnosis of RLS was also made in 60 cases during phase 2. Conclusions: We defined the prevalence of RLS as $9.71 \%$ among 40 years of age and older population. The prevalence of RLS did not differ by age and was 2.6 times more in women. None of the patients were diagnosed as RLS sought medical care for the symptoms, possibly due to lack of knowledge of patients and physicians about RLS. Prevalence studies help to provide knowledge on morbidity, which is essential for diagnosis and early treatment.
\end{abstract}

Key words: Movement disorder, prevalence, restless legs syndrome

\section{Introduction}

Movement disorders have negative effects on the daily physical abilities and quality of life of the patients. ${ }^{[1,2]}$ Restless leg syndrome (RLS) is a sensorimotor disorder characterized by abnormal leg sensations at rest and irresistible urge to move the affected legs, mainly at night, and usually associated with sleep disturbances. ${ }^{[3,4]}$ Prevalence rates of RLS varied between $0.1 \%$ and $24 \%$ among different studies. ${ }^{[3-6]}$ To the best our knowledge, only one epidemiologic study related to prevalence and clinical features of the RLS was carried out in Turkey ${ }^{[5]}$ We conducted a prevalence study of RLS and the clinical feature by using the International RLS Study Group (IRLSSG) ${ }^{[7]}$ criteria in a Turkish population aged 40 years and above.

\section{Materials and Methods}

Bursa is the fourth largest, industrially and socio-econo mically developed city in Turkey with a population of 2, 125, 140 (2000 census). The population of Orhangazi district, where the study has been conducted was 44,426 . The study was carried out between 2004 and 2005 in people aged 40 and above living in Orhangazi district. Projected population for the year 2004 and the sample 
size were calculated based on the population census of 2000. The projected number of subjects aged 40 years and above for the year 2004 in Bursa would be 35.3\% (36.2\% women, $34.4 \%$ men) of the total population and for Orhangazi $27.2 \%$ ( $26.6 \%$ women, $27.7 \%$ men). The anticipated prevalence of RLS was 15 per 100 for sample size calculation. ${ }^{[5,8,9]}$

A multi-step stratified, cluster sampling method was used for subject selection. In the first step, areas were classified according to Orhangazi district, and the number of people aged 40 and above living in each of these areas was calculated. Random sampling was made among these areas according to the proportional size of the age groups. Study gender ratio was also adjusted according to the population gender ratio in Orhangazi. Streets were chosen randomly. Houses with even numbers were visited first and followed by odd-numbered houses. When the required number of subjects for that area was reached, our researchers moved to the next area and used the same method.

All the researchers involved in the screening researchers attended a one-day clinical education course on RLS prior to the study. The study was planned in two phases. In phase 1 , three public health and three neurology residents did door-to-door interview of all the inhabitaall cases were visited at their homes and screened face-to-face by three public health and three neurology residents. During screening, the participants were given a questionnaire including the questions regarding the symptoms of movement disorders and chronic diseases [Figure 1]. Subjects, who answered at least one question positively, were selected for phase 2 screening.

In phase 2, movement disorder specialists assessed those subjects which had a suspected RLS symptom. Diagnosis of RLS was established in subjects with suspected RLS using International Restless Legs Syndrome Study Group (IRLSSG) diagnostic criteria including: (1) urge to move the legs, usually accompanied or caused by uncomfortable leg sensations; (2) temporary relief with movement, partial or total relief from discomfort by walking or stretching; (3) onset or worsening of symptoms at rest or inactivity, such as when lying down or sitting; (4) worsening or onset of symptoms in the evening or at night. The subjects with definitive RLS completed the RLS scale [Figure 2]. In the present study, the questionnaires were filled out by the assistants according to the response of the participants.

Ethics Committee approval was obtained and the subjects gave a fully informed consent to participate.

\section{Statistical analysis}

Statistical analyses were carried out using SPSS v 11.0

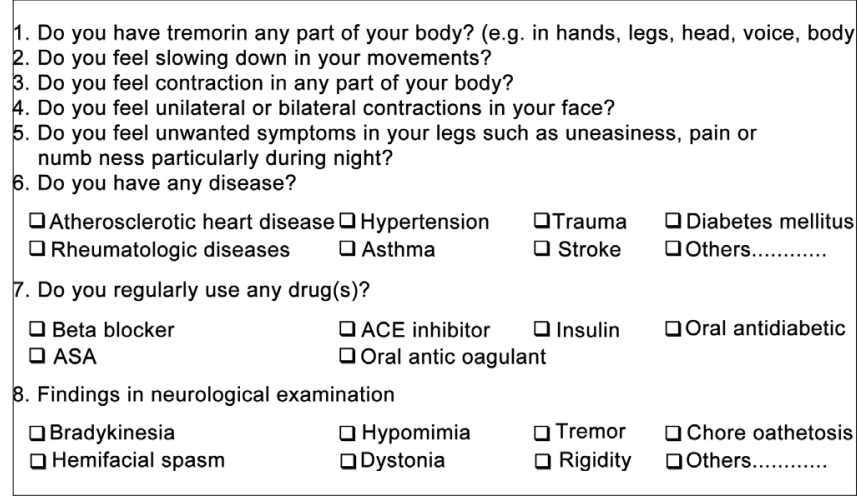

Figure 1: Short questionnaire for movement disorders

for Windows statistical package (SPSS Inc., Chicago, IL, US). The continuous variables are expressed as mean \pm standard error (SE) or standard deviation (SD) and categorical ones are expressed in terms of frequency and percentage $(\mathrm{n}, \%)$. The Pearson's Chi-square and Student's $t$ tests, Mann-Whitney and Kruskall Wallis tests were employed for comparisons. Logistic regression analysis was used. A $P$ value of less than 0.05 was considered statistically significant. Sample size was calculated with the following formula:

$n=N Z^{2} p(1-p) / d^{2}(N-1)+Z^{2} p(1-p)$

where $\mathrm{N}$ is the number of population, $\mathrm{Z}$ is the $\mathrm{Z}$ statistic for $95 \%$ confidence level, $n$ is the sample size, $p$ is the probability of occurrence and $\mathrm{d}$ is the precision:

\section{Results}

Of the 1,256 subjects screened in phase 1, 1,124 (89.6\%) subjects were included in the study. Mean age $( \pm \mathrm{SE})$ of the subjects screened in phase 1 was $57.8 \pm 0.3$ years (range, 40 - 95 years). Of these, 574 (51.1\%) were females (mean age $56.6 \pm 0.4$ years) and $550(48.9 \%$ ) were males (59.8 \pm 0.5 years). Of the 161 subjects with suspected RLS, clinical ascertainment could not be done in phase 2 in 49 (30.4\%) subjects. The reasons included: The subjects could not be reached at their addresses or refused to participate in the study. Of the remaining patients with suspected RLS, diagnosis of RLS could be established in 60 (48 women; mean age, $54.2 \pm 10.3$ years, range, $41-83$ years) in phase 2 . The crude prevalence of RLS was 9.71\% [Table 1], people aged $50-59$ years had the highest prevalence (11.71\%). Restless leg syndrome was 2.6 times more in women $(95 \% \mathrm{CI}=1.2-5.6)$. None of the patients diagnosed in the survey had sought medical attention for RLS prior to the study. The associated significant co-morbidities included coronary heart disease (CAD) and bronchial asthma.

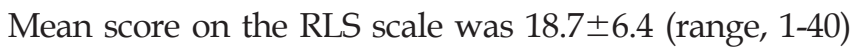




\begin{tabular}{|c|c|c|c|c|c|}
\hline & $\begin{array}{c}0- \\
\text { None } \\
\end{array}$ & $\begin{array}{c}1- \\
\text { Mild }\end{array}$ & $\begin{array}{c}2- \\
\text { Moderate } \\
\end{array}$ & $\begin{array}{c}3- \\
\text { Severe } \\
\end{array}$ & $\begin{array}{c}4- \\
\text { Severe } \\
\end{array}$ \\
\hline \multicolumn{6}{|l|}{$\begin{array}{l}\text { Overall, how would you rate the RLS } \\
\text { discomfort in your legs or arms? }\end{array}$} \\
\hline \multicolumn{6}{|l|}{$\begin{array}{l}\text { Overall, how would you rate the need to } \\
\text { move around because of your RLS } \\
\text { symptoms? }\end{array}$} \\
\hline $\begin{array}{l}\text { Overall, how much relief of your RLS arm } \\
\text { or leg discomfort did you get form moving } \\
\text { around? }\end{array}$ & No RLS & $\begin{array}{c}\text { Complete } \\
\text { or almost } \\
\text { complete } \\
\text { relief }\end{array}$ & $\begin{array}{l}\text { Moderate } \\
\text { relief }\end{array}$ & Mild relief & No relief \\
\hline \multicolumn{6}{|l|}{$\begin{array}{l}\text { How severe was your sleep disturbance due } \\
\text { tp your RLS symptoms? }\end{array}$} \\
\hline \multicolumn{6}{|l|}{ How severe was your RLS as a whole? } \\
\hline How often did you get RLS Symptoms? & 0 & $\begin{array}{c}\leq 1 \\
\text { time/wk }\end{array}$ & $\begin{array}{c}2-3 \\
\text { times/wk }\end{array}$ & $\begin{array}{c}4-5 \\
\text { time/wk }\end{array}$ & $\begin{array}{c}\begin{array}{c}6-7 \\
\text { time/wk }\end{array} \\
\end{array}$ \\
\hline $\begin{array}{l}\text { When you had RLS symptoms how severe } \\
\text { were they on an average day? }\end{array}$ & 0 & $\begin{array}{l}\text { Symptoms } \\
\text { during } \leq 1 \\
\text { hr/day }\end{array}$ & $\begin{array}{l}\text { Symptoms } \\
\text { during } 1-3 \\
\text { hr/day }\end{array}$ & $\begin{array}{l}\text { Symptoms } \\
\text { during } 3-8 \\
\text { hr/day }\end{array}$ & $\begin{array}{l}\text { Symptoms } \\
\text { during }>8 \\
\text { hr/day }\end{array}$ \\
\hline \multicolumn{6}{|l|}{$\begin{array}{l}\text { Overall, how severe was the impact of your } \\
\text { RLS symptoms on your ability to carry out } \\
\text { your daily affairs-for example,carrying } \\
\text { out a satisfactory family,home,social, } \\
\text { school, or work life? }\end{array}$} \\
\hline \multicolumn{6}{|l|}{$\begin{array}{l}\text { How severe was your mood distrubances } \\
\text { due to your RLS sympotoms -for example } \\
\text { angry depressed,sad,anxious, or irritable? }\end{array}$} \\
\hline Total & & & & & \\
\hline
\end{tabular}

1-10 Mild, 11-20 Moderate, 21-30 Severe, 31-40 Very severe

Figure 2: International restless leg syndrome rating scale

\begin{tabular}{|c|c|c|c|c|}
\hline $\begin{array}{l}\text { Age } \\
\text { groups }\end{array}$ & $\begin{array}{c}\text { Female } \\
(n)\end{array}$ & $\begin{array}{c}\text { Male } \\
\text { (n) }\end{array}$ & $\begin{array}{c}\text { Total } \\
(\%)\end{array}$ & $\begin{array}{c}\text { Prevalence } \\
\text { (\%) }\end{array}$ \\
\hline $40-49$ & 22 & 2 & $24(40)$ & 8,66 \\
\hline $50-59$ & 14 & 5 & $19(31,7)$ & 11,71 \\
\hline $60-69$ & 9 & 1 & $10(16,7)$ & 9,02 \\
\hline 70 and over & 3 & 4 & $7(11,7)$ & 10,65 \\
\hline Total & 48 & 12 & 60 & 9,71 \\
\hline
\end{tabular}

[Table 2], mean symptom duration was $5.9 \pm 4.83$ years (range, $1-25$ years). In $48.3 \%$ of patients $(n=29)$, the symptoms were of moderate degree. The symptom frequency was less than a day in a week in $14(23.3 \%)$ patients; two or three days in a week in $24(40 \%)$ patients and four to five days in a week in $11(18.3 \%)$ patients, and six to seven days in a week in $10(16.7 \%)$ patients. Duration of symptoms was less than 1 hour per day in $18(30 \%)$ patients, between 1-3 hours per day in 26 (43.3\%) patients, between 3-8 hours per day in $14(23.3 \%)$ patients, and more than 8 hours per day in $1(1.7 \%)$ patient. Additionally, increase in age was not associated with the symptom severity and duration. None of the patients were admitted to the neurology wards or treated for the RLS. Nine patients were admitted to the medicine wards for the RLS symptoms, but unfortunately the disease was not diagnosed.

On RLS evaluation scale 57 patients had symptoms related to sleep disorder. Sleep disorder was severe in $13(21.7 \%)$ patients, moderate in $25(41.7 \%)$ patients, and mild in $19(31.7 \%)$ patients. Three (5\%) patients did
Table 2: International restless legs syndrome study group scores of the cases with restless leg syndrome

\begin{tabular}{lllll}
\hline IRLSSG & $\mathbf{1 - 1 0}$ & $\mathbf{1 1 - 2 0}$ & $\mathbf{2 1 - 3 0}$ & $\begin{array}{l}\mathbf{3 1 - 4 0} \\
(\mathbf{\%}, \mathbf{n})\end{array}$ \\
\hline$\%, \mathbf{n}$ & $8,3(5)$ & $48,3(29)$ & $36,7(22)$ & $5(5)$ \\
\hline
\end{tabular}

not have any symptoms related to sleep disorder. There was a significant linear association between the scores obtained from RLS scale and frequency of symptoms related to the sleep disorder $(P<0.05)$.

\section{Discussion}

The reported prevalence of RLS in European countries ranges between $5 \%$ and $15 \%$, whereas it is considerably low, $0.1-2.3 \%$, in Asian countries. ${ }^{[3,8,10-12]}$ The prevalence rate reported in the earlier study form Turkey was 3.19\%. This study included subjects aged above 18 years. ${ }^{[5]}$

Whereas we included subjects aged 40 years and above. This may explain the higher prevalence rate, $9.71 \%$ in our study. The prevalence rate in this study is higher than the prevalence rates reported in Asian countries, but similar to the prevalence rates in European populations. This may partly be attributed to ethnic, genetic, and environmental differences. Higher prevalence rates have been reported with increasing age in some studies ${ }^{[1,4,10,13]}$ and no such relation in other studies. owever, similar to our findings there are also reports concerning the lack of correlation between the age and RLS prevalence. ${ }^{[5,8]}$ 
In our study the frequency of certain co-morbidities chronic bronchial asthma and CAD was significantly high. In the other studies the reported associated co-morbidities were diabetes mellitus, cardiovascular diseases, anemia, affective disorders, hypertension, headache, and insomnia. ${ }^{[3,8,11-19]}$ This difference may be related to the study population in different studies. Sleep-related complaints and symptoms are most common in patients with RLS. Polysomnographic studies in patients with RLS help to determine the types of sleep disorders and these include sleep dissociation, rapid eye movement sleep-related (REM) and nonREM sleep-related disorders, daytime sleepiness, and increased sleep latency. ${ }^{[20]}$ Most often the sleep disorders are of moderate severity on the IRLSSG scale scores as seen in our study.

Chronic venous diseases of the lower extremity are reported more frequently among female patients with RLS, ${ }^{[19]}$ whereas hypertension and cardiovascular diseases are reported more frequently in male patients. ${ }^{[11]}$ The cardio-protective effect of the estrogen hormone seems to underlie this gender difference. In our study, similar to the other studies the disease was more common in females. However, we have not found any significant gender differences in the frequency of co-morbidities.

The reported variation in the prevalence rates is generally attributed to the differences in the methodology. In our study, clinical diagnosis of RLS was ascertained (phase 2) in only $37.3 \%$ of the suspected cases in phase 1 study. This low rate of case ascertainment may be related to the face-to-face evaluation performed by the specialists in the diagnostic work-up in phase 2 in our study. The prevalence studies using phone-mail-based evaluation of the questionnaires reported higher rates in the range of $5.5 \%$ and $24 \%{ }^{[6,11,15,16]}$ In the studies conducted by face-to-face interview the reported prevalence rates ranged between $2.3 \%$ and $12.1 \%{ }^{[4,5,8,19,20]}$ and in phase 2 studies conducted by face-to-face interview methods the reported prevalence rates ranged between $0.1 \%$ and $1.06 \%$ [Table 3]. ${ }^{[3,10]}$

In the present study none of the patients had either the diagnosis or treatment of RLS prior to this study. This suggests that there is lack knowledge and awareness of symptoms of RLS among this population and also probably among the practicing physicians in this area. We feel as RLS is associated with poor quality of life, an awareness about this disease should be brought about among the general public and also among the practicing physicians. The limitations of our study include: Small sample size, screening of subjects in a restricted area and the inability to reach all members of the targeted population. The major strength of our study is case

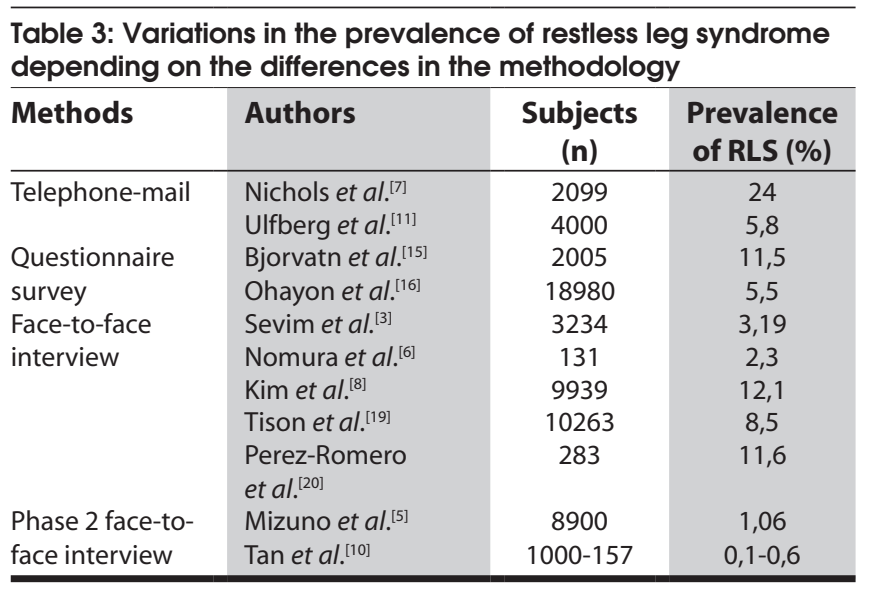

ascertainment by the specialists in phase 2 of the study and our study population represents the demographic composition of Turkey.

\section{References}

1. Moghal S, Rajput AH, Meleth R, D'Arcy C, Rajput R. Prevalence of movement disorders in Institutionalized elderly. Neuroepidemiology 1995; $14: 297-300$.

2. Wenning GK, KIechl S, SeppI K, Muller J, Hogl B, Saletu M, et al. Prevalence of movement disorders in men and women aged 50-89 years (Bruneck Study cohort): A population-based study. Lancet Neurol 2005;4:815-20.

3. Mizuno S, Miyaoka T, Inagaki T, Horiguchi J. Prevalence of restless legs syndrome in non-institutionalized Japanese elderly. Psychiatry Clin Neurosci 2005;59:461-5.

4. Nomura T, Inoue Y, Miyake M, Yasui K, Nakashima K. Prevalence and clinical characteristics of restless legs syndrome in Japanese patients with Parkinson's disease. Mov Disord 2006;21:380-4.

5. Sevim S, Dogu O, Camdeviren H, Bugdayci R, Sasmaz T, Kaleagasi H, et al. Unexpectedly low prevalence and unusual characteristics of RLS in Mersin, Turkey. Neurol 2003;61:1562-9.

6. Nichols DA, Allen RP, Grauke JH, Brown JB, Rice ML, Hyde PR, et al. Restless legs syndrome symptoms in primary care: A prevalence study. Arch Intern Med 2003;163:2323-9.

7. Walters AS, LeBrocq C, Dhar A, Hening W, Rosen R, Allen RP, et al. and International Restless Legs Syndrome Study Group. Validation of the International Restless Legs Syndrome Study Group rating scale for restless legs syndrome. Sleep Med 2003;4:121-32.

8. Kim J, Choi C, Shin K, Yi H, Park M, Cho N, et al. Prevalence of restless legs syndrome and associated factors in the Korean adult population: The Korean Health and Genome Study. Psychiatry Clin Neurosei 2005;59:350-3.

9. O'Keeffe ST, Noel J, Lavan JN. Restless legs syndrome in the elderly. Postgrad Med J. 1993;69:701-3.

10. Tan EK, Seah A, See SJ, Lim E, Wong MC, Koh KK. Restless legs syndrome in an Asian population: A study in Singapore. Mov Disord 2001;16:577-9.

11. Ulfberg J, Nystrom B, Carter N, Edling C. Prevalence of restless legs syndrome among men aged 18 to 64 years: An association with somatic disease and neuropsychiatric symptoms. Mov Disord 2001;16:1159-63.

12. Ulfberg J, Nyström B, Carter N, Edling C. Restless legs syndrome among working-aged women. Eur Neurol 2001;46:17-9.

13. Skomro RP, Ludwig S, Salamon E, Kryger MH. Sleep complaints and restless legs syndrome in adult type 2 diabetics. Sleep Med 2001;2:417-22.

14. Banno K, Delaive K, Walld R, Kryger M. Restless legs syndrome in 218 patients: Associated disorders. Sleep 2000;1:221-9. 
15. Bjorvatn B, Leissner L, Ulfberg J, Gyring J, Karlsborg M, Regeur L, et al. Prevalence, severity and risk factors of restless legs syndrome in the general adult population in two Scandinavian countries. Sleep Med 2005;6:307-12.

16. Ohayon MM, Roth T. Prevalence of restless legs syndrome and periodic limb movement disorder in the general population. J Psychosom Res 2002;53:547-54.

17. O'Keeffe ST. Restless legs syndrome. A review. Arch Intern Med 1996;156:243-8.

18. Phillips B, Young T, Finn L, Asher K, Hening WA, Purvis C. Epidemiology of restless legs symptoms in adults. Arch Intern Med
2000;160:2137-41.

19. Tison F, Crochard A, Leger D, Bouee S, Lainey E, El Hasnaoui A Epidemiology of restless legs syndrome in French adults: A nationwide survey: The INSTANT Study. Neurol 2005;65:239-46.

20. Pérez-Romero T, Comas-Fuentes A, Debán-Fernández M, GonzálezNuevo Quiñones JP, Maujo-Fernández J. Prevalence of restless legs syndrome at the office in primary health care. Rev Neuro $2007 ; 44: 647-51$

Accepted on 02-07-2009

Source of Support: Nil, Conflict of Interest: None declared.

\section{Author Help: Reference checking facility}

The manuscript system (www.journalonweb.com) allows the authors to check and verify the accuracy and style of references. The tool checks the references with PubMed as per a predefined style. Authors are encouraged to use this facility, before submitting articles to the journal.

- The style as well as bibliographic elements should be $100 \%$ accurate, to help get the references verified from the system. Even a single spelling error or addition of issue number/month of publication will lead to an error when verifying the reference.

- Example of a correct style

Sheahan P, O'leary G, Lee G, Fitzgibbon J. Cystic cervical metastases: Incidence and diagnosis using fine needle aspiration biopsy. Otolaryngol Head Neck Surg 2002;127:294-8.

- Only the references from journals indexed in PubMed will be checked.

- Enter each reference in new line, without a serial number.

- Add up to a maximum of 15 references at a time.

- If the reference is correct for its bibliographic elements and punctuations, it will be shown as CORRECT and a link to the correct article in PubMed will be given.

- If any of the bibliographic elements are missing, incorrect or extra (such as issue number), it will be shown as INCORRECT and link to possible articles in PubMed will be given. 